Article

\title{
Reflections on Deploying Community-Driven Visualisations for Public Engagement in Urban Planning
}

\author{
Sebastian Weise ${ }^{1,2, *}$, Alexander Wilson ${ }^{1,3}$ and Geoff Vigar ${ }^{1}$ \\ ${ }^{1}$ School of Architecture, Planning and Landscape, Newcastle University, Newcastle upon Tyne, NE1 7RU, UK; \\ E-Mails: sebastian.weise@newcastle.ac.uk (S.W.), alexander.wilson@newcastle.ac.uk (A.W.), \\ geoff.vigar@newcastle.ac.uk (G.V.) \\ 2 PlaceChangers Ltd., Newcastle upon Tyne, NE1 2HF, UK \\ ${ }^{3}$ Open Lab, School of Computing Science, Newcastle University, Newcastle upon Tyne, NE1 7RU, UK \\ * Corresponding author
}

Submitted: 11 March 2020 | Accepted: 25 May 2020 | Published: 26 June 2020

\begin{abstract}
Publicly available visualisations play an increasing role in enabling wider audiences to contribute to debates to shape place futures. In this article, we unpack such contributions to consider the conceptualisation, actualisation and deployment of these visualisations as separate entities that each require development and reflection. In doing so we draw on our experiences of using two public engagement tools that utilise visualisations of residents' comments. Through this we explore the limitations of visualisations in public engagement designed to support differing levels of debate and their abilities to support abstract topics and geographic associations. We discuss how visualisations alone do not produce actions and how they need to be rooted in wider conversations about a place to lead to insights and action. The article calls for the linking of visualisations for place meaning and place action at different stages of much broader public engagement projects to unlock the potentials present in them in the mediatisation of built environment outcomes.
\end{abstract}

\section{Keywords}

digital visualisations; knowledge exchange; public engagement; town planning

\section{Issue}

This article is part of the issue "Visual Communication in Urban Design and Planning: The Impact of Mediatisation(s) on the Construction of Urban Futures" edited by Gabriela Christmann (Leibniz Institute for Research on Society and Space, Germany), Christoph Bernhardt (Leibniz Institute for Research on Society and Space, Germany) and Jörg Stollmann (TU Berlin, Germany).

(C) 2020 by the authors; licensee Cogitatio (Lisbon, Portugal). This article is licensed under a Creative Commons Attribution 4.0 International License (CC BY).

\section{Mobilising Participation with Visualisations}

Post-war planners saw little relevance or need for citizen participation-planning was a science that could be applied to cities through gathering information and making strategic plans (Jacobs, 1961). Latterly, the desire for public participation in planning has become mainstream in discussions in many nations, although there are often doubts as to the actual commitment of planners and politicians to such practices. Where commitment exists, a great deal of attention has shifted to- ward finding efficient and effective methods for participation, particularly of hard to reach groups (Bishop, 2015). Visualisations and associated digital technologies represent some of the most recent attempts to support citizen engagement and knowledge exchange in planning (Batty, 2001).

Regardless of methods used, a universal feature when engaging citizens in planning lies in how citizens' understanding of place can be integrated with formal, expert-driven processes (Fischer, 2000). In theory, publicly available visualisations of place-based discussions 
could support wider audiences participating in questions concerning place futures. For example, with the growing role and availability of technology, citizens are able to create their own visualisations as tools for action (Manuel, Vigar, Bartindale, \& Comber, 2017; Puussaar, Johnson, Montague, James, \& Wright, 2018), and apply pressure to shape planning outcomes. With this comes a subtle change in the role of visualisations-from one that was used by experts to display results for their expert peers, to using visualisations through which the public may express themselves. In turn this requires rethinking the role of the visualiser, from one who creates ready-made visualisations to one who crafts the context within which public input becomes visible.

Given this shift, and the opportunities offered by the emergence of new digital technologies, we focus on the role of the visualiser (the person generating the visualisations) and their role in supporting knowledge exchange in town planning using two engagement tools we designed. When speaking of the role of the visualiser we refer to our role in mobilising engagement through public visualisations provided by these engagement tools. The engagement tools used two different strategies to visualise community input: JigsAudio creates a visual mural without spatial relation, and PlaceChangers creates an annotated map with an explicit spatial relationship. The engagement tools were used to facilitate conversations around place meaning (values shared in relation to a place) and place action (desired changes) in two engagement projects, which we explore through three research questions:

- What roles did the visualiser take in the creation of the public visual artefact?

- How did the characteristics of the spatial and nonspatial visualisations influence the types of engagement with place?

- How might public visualisations create a space for the discussion of alternative views of place?

Based upon these two case studies, we contribute to a discussion on understanding the act of visualising, and the bearing this has on how citizens engage with planning.

\section{Background: Mediatisation, Visualisations and Knowledge Exchange}

\subsection{The (Re)Presentation of the Urban in Visualisations}

Tufte (2001), a pioneer in the field of data visualisations, referred to visualisations as the graphical display of quantitative information in charts. He argues that by drawing on our ability to unpick patterns in visual imagery (more easily than rows of numbers), visualisations aid in the understanding of complex relationships in data. An example of the power of visualisations of quantitative information of urban space is presented in Szell's
(2018) "visual assessment of space imbalance" in transport infrastructure of major global cities. However, in planning, the concept of visualisation goes beyond statistical relationships, and emphasises the presentation of geographical and increasingly geometrical relationships pertaining to the real-world. In this context, visualisations refers to different ways of sharing information through "drawings, maps, perspectives, 3D physical scale models, computer visualisation models, and scientific visualisation" (Pietsch, 2000, p. 521), as well as a wide range of visual methods to collect this information, such as through sketches, colleagues, photo collections (Al-Kodmany, 2002) and mapping activities (Kingston, Carver, Evans, \& Turton, 2000)

Al-Kodmany (2002) shows how analogous visual methods, such as sketching on paper, relate to computersupported methods of visualising, such as drawing plans digitally-demonstrating a continuum between digital and non-digital visualisations. When creating visualisations for public engagement, there are three key attributes that characterise any visualisation depicting the real-world. Pietsch (2000) notes those characteristics as level of 'abstraction,' 'accuracy' and 'realism.' Abstraction describes the level of detail show of the real world. For example, a building may be presented as a cube or with its detailed facade. Realism refers to the level of visual similarity or mimicry to the real world, for example, through textures and physique. Lastly, accuracy discusses the extent to which information represents the real world in scale and positioning. Seen from this perspective, it is possible to relate simple sketches and detailed drawings into a continuum of visual presentation techniques. Within these parameters, the visualiser has important decisions to make-whether to radically simplify a model of reality or to present reality more closely.

Understanding the implications for visualisation and engagement in planning, the gradient between spontaneous and scientific visualisations are one of the key decisions in using visualisations for knowledge exchange (Al-Kodmany, 2002). In public engagement, abstract techniques offer creative freedom for participants, but can be hard to interpret by planners. On the other hand, visualisations that depict the real-world with high levels of accuracy and realism, may be hard to interpret (Watson, 2020). Engagement methods need to capture a range of knowledges, both experiences of places and expert knowledge, perhaps requiring different visualisations for different engagement stages or objectives. For instance, the local knowledge of residents, and of value to planning outcomes, is less amenable to being depicted in highly accurate visualisations. Effective knowledge exchange is challenging if insights cannot be combined, especially everyday experiences of places and planningspecific expertise (Natarajan, 2017). Therefore, while Hemmersam, Martin, Westvang, Aspen, and Morrison (2015) state that visualisations in planning are essential in supporting knowledge exchange, the visualisation needs to align with its purpose. 


\subsection{Emerging Visualisations in Digital Civic Engagement in the UK}

Historically, visualisations have always played a key role in planning especially through physical models and maps. However, the role of public engagement in planning remained weak. In the UK, the Skeffington Report of 1969 critiqued the established approach to planning, leading to legislation on public participation in planning. In the report, the committee laid out a series of measures planners could adopt to provide new opportunities for citizens to be involved in planning. Increasing demands for citizens to engage in planning have not been accompanied by great systematic success in doing so (Bishop, 2015). One response was to look towards visualisations that were simpler to read to support nonexpert understandings and solicit feedback on proposals. Visualisations changed to reflect this-they were no longer to be used only by experts, but increasingly for external stakeholders, citizens and politicians to understand as well. For instance, Batty (2007, p. 326) noted that "spatial databases...(took) pride of place only in the 1990s while the use of graphics and the web for dissemination and participation has only become significant very recently."

Methods for engaging citizens in town planning online are a recent phenomenon driven by the maturing of web technologies in the early 2000s (de Lange \& de Waal, 2013). Technologies have been explored to understand their value in making people aware of the potential consequences of a development (Batty, 2001; Dambruch \& Krämer, 2014). Interactive web technologies (Web 2.0) allow people to view and comment on proposals, rather than needing to travel somewhere (Wilson, Tewdwr-Jones, \& Comber, 2019). However, many visualisations used in planning remain designed by experts for other experts or privileged users (such as other planners, their clients, or people with influence) rather than for citizen understanding. This makes it necessary to build critical understandings of how those visualisations are used for engagement.

\subsection{New Directions in Digital Civic Engagement with Public Visualisations}

Early technologies for participation in planning typically used maps-based visualisations that planners could interrogate to understand citizen opinions (Nuojua, 2010). Approaches using map-based visualisations have undergone multiple iterations, drawing on mobile apps, such as in the case of Mobile Democracy that explored 'situated action' that couples engagement through a smart phone that respond to physical tags (Bohøj, Borchorst, Bødker, Korn, \& Zander, 2011), or more recently, engagement with nearby planning issues using smart watches (Wilson et al., 2019). Furthermore, the emergence of open cartographic systems, such as OpenStreetMap, allows mapping to become more engaging and interactive
(Haklay \& Weber, 2008). Research on spatial data systems is evolving rapidly towards the development of shared development environments for cities and its technical foundations (Nourian, Martinez-Ortiz, \& Ohori, 2018).

Whilst most digital participation technologies use map-based approaches through mobile devices, there is a growing opportunity for those that avoid screenmediated engagement and encourage participation with visualisations that are physical, in public spaces and nonspatial (Koeman, Kalnikaitè, Rogers, \& Bird, 2014). The exploration of visual media to express matters of concern in images and sketches for instance (Johnson et al., 2017; Wilson \& Tewdwr-Jones, 2019) are accessible and engaging, and draw on co-located modes of engagement. Other work, such as Taylor et al.'s (2015) Tenison Road Project, encouraged residents and visitors of a road to co-create data archives related to their street. They explored novel forms of displaying data with large responsive electronic pie charts and bar graphs alongside electronic voting devices in residents' homes. These methods go beyond an efficiency-driven approach to visualisation into approaches that can generate interest and encourage engagement. These examples illustrate the opportunities of non-app and non-screen-based systems to support engagement with place-based concerns.

\section{Method: Relating Insight from Two Engagement Tools}

To explore the role of the visualiser we refer to two case studies of public visualisations using the PlaceChangers and JigsAudio engagement tools to reflect on visualisations for community engagement in planning. We took a 'design research' approach which is concerned with generating insights on social phenomena through making prototypes (Frayling, 1993). Archer (1981, p. 30) defines design as "the combined embodiment of configuration, composition, structure, purpose, value and meaning in man-made things and systems." We separately designed two public engagement tools that employ visualisations in different ways to support engagement in planning and deployed them in 'in the wild' to understand the use of the technologies in context. We reflect critically on the function and role of the visual artefacts and explore the relationships between the social context and the designed artefacts (Cross, 1999) based on two deployments.

\subsection{Analysis Framework}

We created a framework of three themes to facilitate the reflection and synthesise insights on the role of the visualiser, the visualisation, and to structure the subsequent case analysis:

- The role of the visualiser: The activities and considerations made by the visualiser and its relationship with other roles on the project. 
- The types of engagement enacted: The interactions observed with those visualisations in participatory processes, especially the modes of engagement, modes of communication for participants and the responses (Maher, Paulini, \& Murty, 2011).

- Nature of the visualisations created: Lastly, we draw on Pietsch (2000) who suggested to characterize visualisation in relation to abstraction, realism, accuracy.

Rather than reflecting on what the technologies encouraged people to share, we explore how the technologies facilitated this, and our involvement, to understand the role of the visualisations in the wider social environment they were used.

\subsection{Description of the Two Public Engagement Tools and Case Studies}

To explore understandings of the technology, we chose to deploy two different technologies with distinct approaches, media, and types of visualisation through which we hoped would encourage different responses, as shown in Table 1. Reflecting the discussion above, JigsAudio was chosen to facilitate open, place-based commentaries about areas, whereas PlaceChangers was used to exemplify an approach based on Euclidean space that required participants to tie comments to places. Our research was initiated based upon the recognition of the complementarity in the researchers' approaches to public engagement.

JigsAudio is a public engagement tool designed to engage communities in discussing their place experiences and aspirations through drawing and talking. To use the device, participants were asked to draw their responses on a jigsaw piece, add an audio recording to their depiction:

The JigsAudio device reads a radio-frequency identification...tag (similar to those used in contactless bank cards) on the jigsaw piece. The participant then records an audio clip (by pressing the record button) that is associated with their jigsaw piece and the piece is then placed within the jigsaw. JigsAudio contains a Raspberry Pi (a bank card-sized computer), [a radiofrequency identification] scanner and a microphone. (Wilson \& Tewdwr-Jones, 2019, p. 6)

Tiles can be placed on the device to listen to the associated audio clip. The audio and visuals are then bought together on a website that shows a community's thoughts on the topic.

PlaceChangers is an online platform designed to extend traditional forms of public consultation with discursive place-based feedback. The platform is based upon research into different formats of engagement that public planners organise to support public consultations during plan making (Weise, 2016). Over four years, the platform developed from a 'tagging game' into an online service based on the premise of discussing places on a map. This type of engagement format is most useful once value-based questions around the purpose and key aims of a design project have been resolved.

\subsection{Limitations}

In this article, we present the experiences of the researchers involved in mobilising participation through the public engagement tools, by taking on the role of the visualiser. Deploying the technologies 'in-the-wild,' rather than in more controlled lab-based studies, meant the work had to be responsive to both the research project and the participants. In each case we provided third parties with the engagement technologies and were not able to observe the technologies throughout all of their uses. We were not able to get the views of those who chose not to participate; however, we had more structured interactions with individuals facilitating the engagement activities and who had direct contact with participants.

\section{Emerging Practices Involved with Public Visualisations in Public Engagement}

In the previous sections we outlined a shift in both planning engagement and visualisation, from expert-driven

Table 1. Overview of JigsAudio and PlaceChangers.

\begin{tabular}{lll}
\hline Example & JigsAudio & PlaceChangers \\
\hline Genealogy of approach & $\begin{array}{l}\text { 'Citizens murals' and photo collections } \\
\text { (McClure, Byrne, \& Hurand, 1997) }\end{array}$ & $\begin{array}{l}\text { PPGIS type systems and approaches (Kingston } \\
\text { et al., 2000; Talen, 2000) }\end{array}$ \\
$\begin{array}{l}\text { Modes } \\
\text { Format of the public } \\
\text { visualisation }\end{array}$ & $\begin{array}{l}\text { A collection of views on a topic wall made } \\
\text { up of sketches and audio clips that can be } \\
\text { played through the JigsAudio device. }\end{array}$ & $\begin{array}{l}\text { A mainly mediated/online } \\
\text { place-change. }\end{array}$ \\
$\begin{array}{l}\text { Format of individual } \\
\text { responses }\end{array}$ & $\begin{array}{l}\text { Tiles made up of sketches/drawings/ } \\
\text { scribbles with accompanying audio } \\
\text { annotations. }\end{array}$ & $\begin{array}{l}\text { Place-based tags made up mainly of text } \\
\text { comments, ratings, or photos, and sets about the } \\
\text { of participant questions place more generally. }\end{array}$ \\
\hline
\end{tabular}


to more participatory. In this section we explore how the tools engaged people in different ways through visualisations. To reflect on the technology deployments, we use the framework introduced earlier: the role of the visualiser; the types of engagement enacted; and the nature of the visualisations created.

\subsection{The Case of Engaging in the Future of Newcastle at the Great North Exhibition-JigsAudio}

JigsAudio was used to encourage a debate about the future of Newcastle during the Great Exhibition of the North, June through September 2018. This special exhibition celebrated arts, culture and design in the North of England. Through JigsAudio visitors were provided with the opportunity to present their ideas, experiences, and aspirations of Newcastle. The aim was to explore how communities created and communicated through their own visualisations on issues that mattered to them, rather than using tools that planners typically use (such as proposal maps or written policy). The work was inspired by previous attempts of getting citizens to express their concerns and aspirations through apps, which were found to over-represent problems, rather than closely-held feelings and wider place-experiences (Wilson et al., 2019). The aim was to encourage longerterm perspectives than apps developed for speed and in-situ participation encouraged and test an open-ended engagement method that encouraged reflection and dialogue. Rather than sending responses to a decision maker, responses would be interpreted and understood by the respondents through a public visualisation within which people documented their feelings through drawing and talking.

\subsubsection{The Role of the Visualiser}

The visualisation within the JigsAudio system led to considerable thought as to how the outcomes from the discussion of the future of Newcastle should be visualised. Because of this, the visualiser (the person designing the activity) had considerable power in shaping how people would approach and respond to the activity based upon its appearance (Norman, 2013; Wilson \& Tewdwr-Jones, 2019)

These considerations included the topic, where the device would be situated within the gallery, how it would be affixed, as well as the shape, aesthetics and layout of the pieces. It was decided the activity would be best situated within an interactive floor of the gallery encouraging people to reflect on the exhibition and communicate their ideas. The pieces were blank 'tiles' that could be hooked to the wall-in previous deployments illustrations already on the piece were used to guide participants that served to narrow-down what people communicated (Wilson \& Tewdwr-Jones, 2019). Here, participants could choose where to place their tiles on the wall. It was decided the activity would be wall- mounted, and the device and headphones mounted to a plinth alongside.

Whilst there were decisions taken about the activity up-front, participants had control over their representations to varying degrees, through choosing colours, materials, modifications, and where to put their piece, leading the visual appearance of the activity changed on a daily basis. Following a nearby crafting activity, it appeared that some had taken the opportunity to decorate their piece with pipe cleaners and felt. At other times there were more pragmatic issues discussed, such as local air quality and transport. As the different users engaged with the activity, the visuals changed. Hooks would become filled, pieces would become scarce or would move around or be placed on top of one another. The constantly evolving and messy display reflected the different ideas, viewpoints and preference of communication of the participants, and presented something that was not static.

\subsubsection{Types of Engagement Enacted}

JigsAudio facilitates differing levels of engagement with the technology and activities. Before engaging, it is worth noting that participants were required to travel somewhere to engage. The barriers, therefore, were relatively high for those wishing to participate (when compared to web-based engagement tools). It was hoped, however, that once engaging with the activity, many of the barriers to expression (such as needing to use prose), to digital technology (having to own and be able to use digital technology) and nervousness (by seeing that others had undertaken the task) could be reduced. In order to facilitate this there were three differing types of engagement that were observed with people engaging with the technology:

- Observer: JigsAudio provided the opportunity for people to stand back and take the visuals in and get a surface-level understanding of the wider representations of the jigsaw pieces, as well as some of the broader concepts coming forward.

- Interactor: For those more interested, people could engage with the pieces individually, may scan and listen to a few of the pieces, and get a more detailed understanding of an individual's perspectives on an issue.

- Creator: After taking in the view of others, some chose to provide their own views on the topics. To do this, people were encouraged to draw their own depiction, add an audio recording, and add it to the collection.

JigsAudio, through encouraging drawing and talking, allowed people to communicate through alternative methods beyond those typically required to participate (such as writing). It was theorised that using these communication methods allowed people to discuss more elaborate 
visions and experiences about place than people might otherwise be communicated when replying on text. The large format of the pop-up exhibition encouraged engagement with the activity without requiring people to visit specific websites or download dedicated apps, and invited participation from those in who would struggle with the formal planning system or digital technology

\subsubsection{Nature of the Visual(s) Created}

The resulting visualisation was a thematic (rather than spatial) representation of people's views on a topic in a mural of tiles (see Figure 1). The broad number of topics represented, and how they were represented, led to an engaging mosaic of viewpoints that could be explored by others through its visuals and audio. The visualisation was unstructured, forming a resource which represented a group's wider-ranging viewpoints.

Given the open nature of the commentaries, further interpretation is required than when compared to the PlaceChangers that used a more conventional mapbased approach. Whilst it was beneficial that people could express their opinions more openly, there were challenges presented when attempts were made to understand the implications of these comments. More abstracted comments were difficult to interpret into deliverable policy proposals that could be engaged with through traditional decision-making processes. In the deployment of JigsAudio, whilst the method did inspire wide-ranging commentaries, it was difficult in some cases to understand where the comments should be directed (for example, the local government department responsible for acting on wider place-based comments). This raises the question as to how far public participation methods should align with the procedural processes of planning within local authorities. There are important considerations about whether, or when, consultation be narrowed. Is it preferable to close down discussions, and have a narrower discussion on the narrower aspects that can be commented on, or, should wider discussions then be focussed at later stages?

\subsection{The Case of Byker Estate Improvement Program-PlaceChangers}

Here we will discuss the opportunities and limitations of a narrower approach to engagement using the PlaceChangers platform deployed in early 2019 on the Byker estate, a large housing estate in the east of Newcastle upon Tyne, UK. The following engagement was predicated around the housing association wanting to establish actionable changes to public spaces, streets, greenspaces, alleyways, playgrounds and other facilities. The estate was large and covered multiple communities in different types of dwellings. Given the size of the area and the diversity of potential concerns, the delivery team wanted to create a resident engagement program that was simple to deploy whilst being able to systematically capture wide ranging concerns.

An interactive public map was used as part of a wider engagement programme consisting of local street stalls, evening workshops with elders, visits to local schools, as well as site visits and walks. The mapping tool within the PlaceChangers platform was chosen by the architect in order to provide more structure to the debate than would otherwise be possible via the existing Twitter channel, which was also used by residents to give feedback on the estate. Subsequently in the delivery of the programme of work, small notices with tags could be scanned by mobile phone cameras placed around the estate as well as online posts with a link to the interactive map.
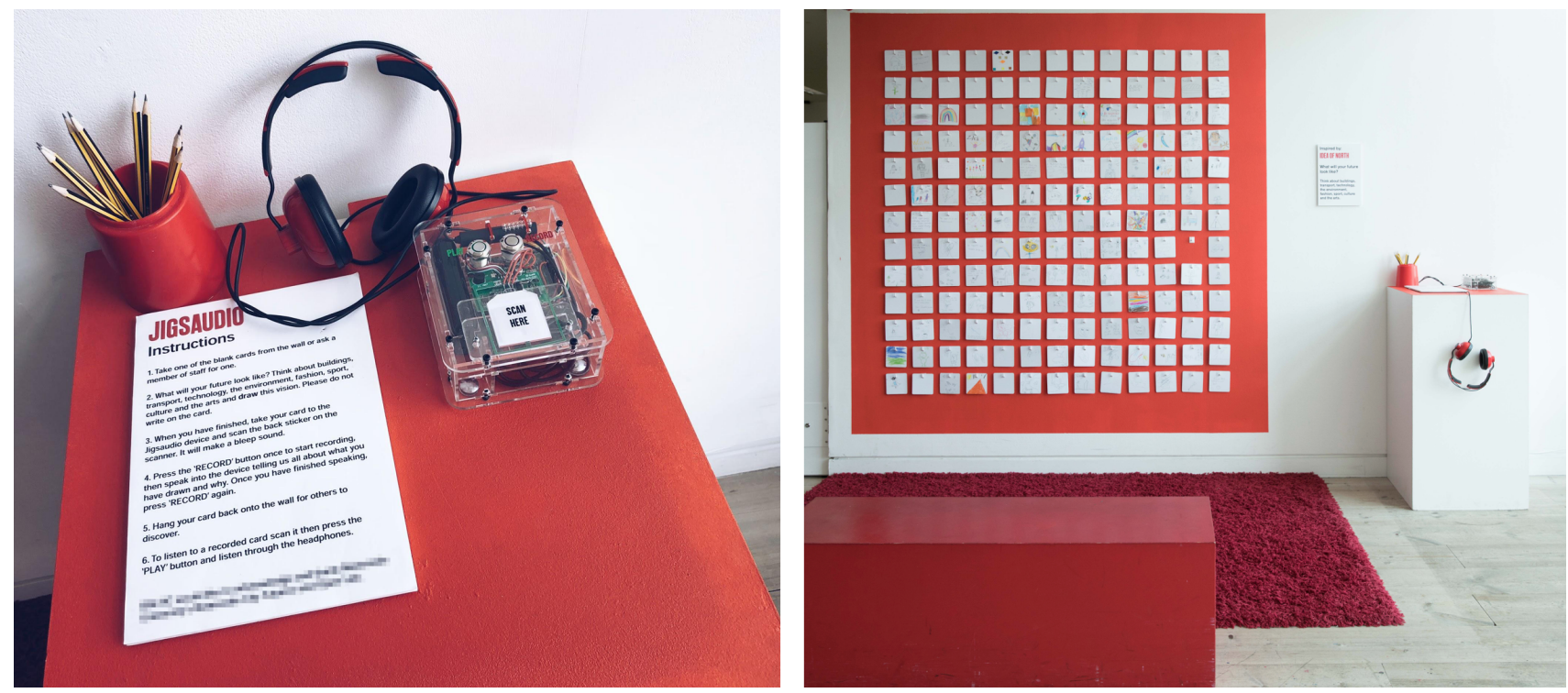

Figure 1. An example of one deployment at a modern art gallery in Gateshead, UK: JigsAudio device (left) and the public visual artefact - a tile mural of individual contributions (right). 


\subsubsection{The Role of the Visualiser}

With the map-based interface, the visualisers, in this case largely the architects guided by the developers of the platform, struggled with the typical concerns mentioned in relation to map-based presentation, including to help individuals orientate, and to shift relevant aspects into focus. The visualiser advised the architecture team on the presentation of the estate and the various focus areas so that it would be familiar to residents. There was also the concern how to ensure that respondents would easily recognise the online campaign as an official part of the resident engagement programme and so a well-used map of the estate was used as an overlay to the standard base map, along with the logo of the relevant organisation.

To create a shared presentation of the estate, the architectural team decided to use a colour-coded map of neighbourhoods that are found widely across the estate as it was thought that this would help residents locate where they are (see Figure 2, left). In addition, a number of well-known communal points of interest were placed on the map of the estate with some extra information. Those points were both used to provide feedback on general areas but also to help with people's orientation. Applying Lynch's (1960) idea of visualisability, this approach emphasised nodes and districts. Districts were heavily abstracted, no longer so much differentiated by their building typology, but by colour coding of neighbourhoods on a map. All responses were summarised under each area of the estate, which later helped to recognise how concerns varied across the area as a whole.

\subsubsection{Types of Engagement Enacted}

Responses were obtained from three architects and approximately 30 local residents through the online map: 491 improvement ideas were submitted. As opposed to solely engaging online, the campaign enabled residents to engage via in-street booths where the architecture team provided a crucial link between the voices and opinions of citizens and their interpretation and referencing in the platform (see Figure 2, right).

Some responses were closely related to specific types of features or locations on the estate, and map-based presentations lend themselves to responses that are more likely to relate to place action as opposed to place meaning. Some responses related to value-based issues, such as the importance of green space, or the social causes of littering, where it was impossible to relate them to any specific location. All responses required detailed reflection and review by a facilitator to relate them to a programme of work with actionable interventions.

The key concerns observed to a large extent related to safety concerns and issues with upkeep, especially litter, bins, and fences etc. The campaign succeeded at flagging a wide range of specific concerns regarding particular areas or features on the estate which, in turn, led to honest feedback on feelings towards the place qualities that could be addressed through design interventions.

\subsubsection{Nature of the Visual(s) Created}

Overall, the map-based visualisation was useful at recording the views of different stakeholders, to keep notes from site visits, and later to help the design team to sift through the responses by accessing responses through the map interface. Annotations were clustered and covered the whole of the estate. The visualisation was seen as an artefact of progress that provided the team with the comfort that a lot of work had been done to capture and document the various insights gained from both the public and the design team. In the followup, the design team got involved in coding all responses with topic keywords to facilitate the analysis, leading to simple summaries of issues in bar charts for each sub area. This translation was essential in communicating the key issues observed on the estate and to create an argument for change.
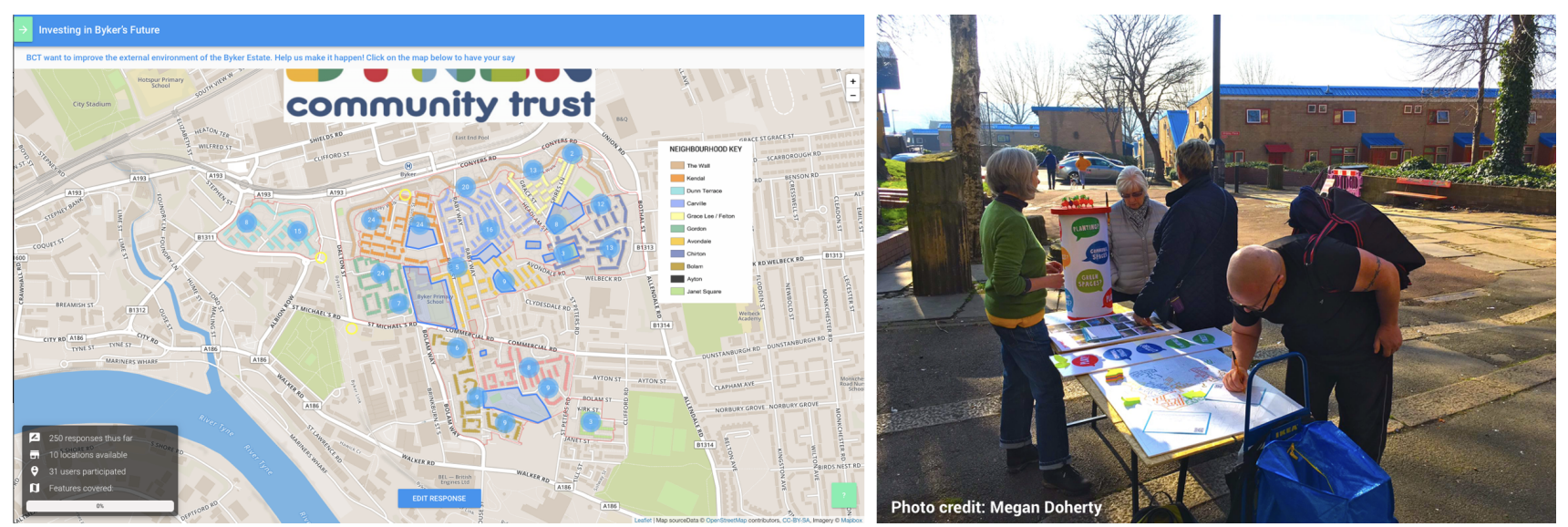

Figure 2. Presentation of the public facing map with various annotations from the public and consultant: the public visual artefact (left) and public event embedding the consultation in a local context (right). 


\section{Insights for Future Work}

\subsection{What Roles Did the Visualiser Take in the Creation of the Public Visual Artefact?}

Reflecting on the two examples, we note that the visualiser played an important role to embed the visualisation in a place-based context. Initially, the visualiser performed activities to set up the visualisation and embed it in the respective context and community by providing the right level of context for public respondents to be able to interpret what they were asked to do and to develop an appropriate response. The aims of the project played an important role in determining which type of visualisation, and its format, would be appropriate. In the PlaceChangers example, where the focus was on ideas for improving an existing estate, this meant to present an abstract map of the estate that shifted different neighbourhoods into focus. With JigsAudio, which aimed to enable a discussion in relation to the value of a place, it meant setting up an environment within which participants could reflect, and respond creatively, without needing to identify specific places. The geographic context here was only implied through cues and prompts provided as part of the engagement activity.

In the aforementioned project examples, the visualiser takes a role different from typical tasks in creating a visualisation. The role of the visualiser here is to anticipate the format of contributions, and the ways in which the contributions made by others are logged, presented, and related in order to enable the creation of a public visual artefact. The visualiser therefore needs to consider guidelines and hints that help others to contribute to the visualisation, regardless of whether the visualiser is present. The contributors themselves will emerge as essential in the creation of the visualisation. In a visualisation driven by public responses, it means that the role of professionals, such as architects and planners, can shift to support the facilitation and interpretation of the content of the visualisations. Therefore, as suggested by Paulini, Murty, and Maher (2013) in collective design processes, an important consideration of the visualiser to make is not solely the form and nature of the public visualisation, but also the likely roles that participants take in the production of that visual. Box 1 provides a few roles that emerged.

\subsection{How Did the Different Characteristics of Spatial and Non-Spatial Visualisations Influence the Types of Engagement with Place Qualities?}

PlaceChangers and JigsAudio abstract a place-based conversation in different ways (see Table 2). As we note from the discussion of the two visualisations, different types of visualisations are likely to evoke a different response that is either more useful for place meaning or place actions. With JigsAudio, there is no explicit mention or use of geographic space in the visualisation. Here individual contributions consist of drawings and audio in response to an open question, that may be more likely to explore values and feelings in relation to a place and therefore are more useful for establishing place meaning. While the PlaceChangers platform is also deployed within a place-based context, responses require explicit spatial references and so require respondents to think about where their opinions relate to and therefore is most useful to consider place action.

Place meaning relates to the interpretation of the place and various views of set priorities; place action may be more around specific, often narrow actions, and the prioritisation of those actions with everybody involved. Typically, at the beginning of any public engagement project in town planning, it is counterproductive to try and tie feedback to locations without any specific focus - rather an approach built around establishing place meaning offers the opportunity to establish broad aspirations and fears to feed into a design project. What seems to be required instead, related to the perspective of 'infrastructuring' community engagement, is an artefact-centric view that accommodates visualisations in an integrated approach that establishes place action based on place meaning. This is exemplified in any design process that begins with fuzzy and abstract problem spaces that later narrows to practical activities and action (Paulini et al., 2013). Naturally, earlier design stages require visualisations with coarser accuracy or realism, and greater abstraction. Later design stages, instead, require visualisations that incorporate a greater degree of

Box 1. Consideration to be given to emerging roles in participatory processes that involve public visual artefacts for participation in town planning.

Visualiser: Shapes the setup and envisions the future digital public visualisation.

Interpreter: Participants and professionals interpreting individual contributions, for example, through tagging.

Facilitator: Participants or professionals to embed the visualisations with engagement activities.

Contributor: Participants or professionals to make additions to the public visualisation.

Observer: Those who enjoy the visualisation and reflect but may not contribute. 
Table 2. Review of the public visual artefacts in JigsAudio and PlaceChangers using the characteristics of visualisations (see Pietsch, 2000).

\begin{tabular}{lll}
\hline Example & Sketch mural & Annotated map \\
\hline Abstraction & $\begin{array}{l}\text { High: On level of individual contribution } \\
\text { and the public visual }\end{array}$ & $\begin{array}{l}\text { Medium: map is abstracted based on built environment, } \\
\text { but does not reflect lived experience }\end{array}$ \\
Realism & Low: Not a requirement for this visual & $\begin{array}{l}\text { Low: Dimensions and spatial placement of build environment } \\
\text { can be seen, but it is clear that it is a map }\end{array}$ \\
Accuracy & Low: Not a requirement for this visual & $\begin{array}{l}\text { Medium: Contributions relate to some location in the } \\
\text { neighbourhood. Accuracy is not a requirement. }\end{array}$ \\
\hline
\end{tabular}

the real world (for instance in terms of constraints) to greater accuracy, realism, and therefore require less abstraction in the place-based relationships they suggest.

\subsection{How Might Public Visualisations Create a Space for the Discussion of Alternative Views of Place?}

As indicated, visualisations with different levels of abstraction encourage different responses-earlier stages of engagement can accommodate wider place-based discussions, whereas later stages require ideas on concrete proposals. It suggests that designers of digital participation technologies need to understand how to encourage people to express their abstract ideas towards place before comments on specific parts of plans are discussed. Parameters become more refined over time, from abstract conceptualisations and ideas become more detailed specified plans. Visualisations only perform well if they present a clear message relative to the purpose, cultural frames, and expertise of the person intended to be engaged. Therefore, in the mediatisation engagement on urban issues and the further exploration of visualisations for public engagement, we suggest Figure 3 for which different visualisations are required.

By the term 'informal engagement' we mean engagement that takes place in informal settings and on topics that are less strictly aligned to formal planning processes, rather than those that require engagement with planning policies and specific proposals. Here public visual artefacts could play a significant role to serve as early conversation starters for built environment projects. The different engagement approaches (from informal to formal engagement) recognise that the shaping of place often falls outside of formal planning processes. Therefore, we need to pay attention towards how we open up informal discussions outside and acknowledge people's ex- periences of place and long-term aspirations with flexible visual tools that are not constrained by formalities (in terms of process), or high levels of precision. A key direction for new methods of engagement is the increasing overlap of digital technology and built environments (McCullough, 2005). Architecture and the built form provide a foundation upon which digital technologies can provide interactivity in future urban spaces that may lie beyond screens and maps.

\section{Towards an Ecology of Public Visualisations for Participation in Planning}

We considered two engagement tools that used publicfacing visualisations to evoke a response from members of the public for a specific planning purpose developed by us. Each of the engagement tools demonstrated public-facing visualisations with different degrees of precision and accuracy in how they depicted aspects of the real world. In the case of JigsAudio, we find a visualisation that evokes responses that are abstract and implicitly linked to a place. Through its physical embedding, the visualisation does not require any specific reference to a place, and thereby offers the opportunity for creative and unconstrained responses. These messier and all-encompassing comments require a vital stage of translation to fit within formal decision-making processes. In order for JigsAudio to form an effective participation method, this step must be carried out by someone close to the participants, who can take the comments and understand them within the context of shared experiences and concepts.

In the case of PlaceChangers, we find a visualisation that is more explicit in terms of the location comments referred to, and therefore requires respondents to raise ideas and responses that are more specific and narrower

$$
\begin{array}{r}
\text { Abstracted Ideas for shaping a Place } \\
\text { The principles of scale and massing } \\
\text { Informal engagement (i.e., aligned with } \\
\text { experiences) }
\end{array}
$$

$\leftrightarrow \quad$ Formal allocations of land to specific uses

$\leftrightarrow \quad$ Detailed architectural plans

$\leftrightarrow \quad$ Formal engagement (statutory required engagement aligned with law and policy)

Figure 3. Levels of abstraction and engagement approaches. 
to a particular location. The visualiser makes important decisions relating to the setup of the initial map canvas, as to what to move into focus, and what to abstract or remove, in order to shape the discussions. Here, too, responses will require interpretation by someone close to the case, in this case architects involved.

We suggest that the first approach is an example of a visualisation that is powerful in evoking discussion about place meanings, that is the values and feelings citizens attach to place. The second approach uses visualisation that evokes responses around specific narrower issues (what is where) and is better suited to place actions, perhaps later in the development of a plan for an area. Future work should look to define when and how visualisations suited for engagement on place meaning (spatially more abstract) with those suited for place action (spatially more explicit) can be linked. We believe that this could strengthen the support for broad informal public discussions and the ability to generate proposals from the bottom up in a manner that can have an influence in the formal processes of the planning system.

The article also highlights the changing role of the visualiser involved in these public engagement projects. Rather than the production of final maps or renderings that present place-based visions, the role of the visualiser shifts towards creating frameworks within which the public can pull contributions together in a process where public visual artefacts arise. Tools for participation should reflect the terms they are engaging people on. These new practices will involve considering how to embed the public visualisation in emergent public engagement projects. It will also involve the creation of formats within which members of the public can co-create public visualisations of what is needed and wanted. Lastly, it will also require negotiating and defining potential roles individuals in the creation of the public visual artefact, and how they relate to project stakeholders. While significant attention has been typically given to professional's collaboration tools, including mapping systems and modelling tools, further research is required on the power of these informal, often more simplistic visualisations in public engagement processes, and the role of the visualiser in these contexts when removed from the realm of the planning professional.

\section{Acknowledgments}

The authors wish to acknowledge the support and assistance of David Maguire, Vicky Sturrs and Gary Malkin at the BALTIC Centre for Contemporary Art, Nicky Watson and the wider team at JDDK, and Kate Percival. The research was undertaken through the EPSRC Digital Civics programme (Ref. EP/L016176/1), and the EPSRC Digital Economy Research Centre (Ref. EP/M023001/1).

\section{Conflict of Interests}

The authors declare no conflict of interests.

\section{References}

Al-Kodmany, K. (2002). Visualization tools and methods in community planning: From freehand sketches to virtual reality. Journal of Planning Literature, 17(2), 189-211. https://doi.org/10.1177/08854120 2762475946

Archer, B. (1981). A view of the nature of design research. In R. Jacques \& J. Powell (Eds.), Design: science, method (pp. 30-47). Guildford: Westbury House.

Batty, M. (2001). Models in planning: Technological imperatives and changing roles. International Journal of Applied Earth Observation and Geoinformation, 3(3), 252-266. https://doi.org/10.1016/S03032434(01)85032-7

Batty, M. (2007). Planning support systems: Progress, predictions, and speculations on the shape of things to come (CASA Working Paper Series 122). London: Centre for Advanced Spatial Analysis.

Bishop, J. (2015). The craft of collaborative planning. London: Routledge.

Bohøj, M., Borchorst, N. G., Bødker, S., Korn, M., \& Zander, P. O. (2011). Public deliberation in municipal planning: Supporting action and reflection with mobile technology. In Proceedings of the 5th International Conference on Communities and Technologies (pp. 88-97). New York, NY: Association for Computing Machinery.

Cross, N. (1999). Design research: A disciplined conversation. Design Issues, 15, 5-10. Retrieved from http:// www.jstor.org/stable/1511837

Dambruch, J., \& Krämer, M. (2014). Leveraging public participation in urban planning with 3D web technology. In Proceedings of the Nineteenth International ACM Conference on 3D Web TechnologiesWeb3D '14 (pp. 117-124). New York, NY: Association for Computing Machinery. https://doi.org/10.1145/ 2628588.2628591

de Lange, M., \& de Waal, M. (2013). Owning the city: New media and citizen engagement in urban design. First Monday, 18(11). https://doi.org/10.5210/fm.v18i11. 4954

Fischer, F. (2000). Citizens, experts, and the environment: The politics of local knowledge. Durham, NC: Duke University Press.

Frayling, C. (1993). Research in art and design. London: Royal College of Art.

Haklay, M., \& Weber, P. (2008). Openstreetmap: Usergenerated street maps. IEEE Pervasive Computing, 7, 12-18.

Hemmersam, P., Martin, N., Westvang, E., Aspen, J., \& Morrison, A. (2015). Exploring urban data visualization and public participation in planning. Journal of Urban Technology, 22(4), 45-64. https://doi.org/ 10.1080/10630732.2015.1073898

Jacobs, J. (1961). The life and death of great American cities. New York, NY: Random House.

Johnson, I. G., MacDonald, A., Briggs, J., Manuel, J., Salt, 
K., Flynn, E., \& Vines, J. (2017). Community conversational: Supporting and capturing deliberative talk in local consultation processes. In Proceedings of the 2017 CHI Conference on Human Factors in Computing Systems-CHI '17 (pp. 2320-2333). New York, NY: Association for Computing Machinery. https://doi.org/ 10.1145/3025453.3025559

Kingston, R., Carver, S., Evans, A., \& Turton, I. (2000). Web-based public participation geographical information systems: An aid to local environmental decision-making. Computers, Environment and Urban Systems, 24, 109-125. https://doi.org/10.1016/ S0198-9715(99)00049-6

Koeman, L., Kalnikaitè, V., Rogers, Y., \& Bird, J. (2014). What chalk and tape can tell us: Lessons learnt for next-generation urban displays. In Proceedings of the International Symposium on Pervasive DisplaysPerDis '14 (pp. 130-135). New York, NY: Association for Computing Machinery. https://doi.org/10.1145/ 2611009.2611018

Lynch, K. (1960). The image of the city. Cambridge, MA: MIT Press.

Maher, M. L., Paulini, M., \& Murty, P. (2011). Scaling up: From individual design to collaborative design to collective design. Design Computing and Cognition, 10, 581-599. https://doi.org/10.1007/978-94007-0510-4_31

Manuel, J., Vigar, G., Bartindale, T., \& Comber, R. (2017). Participatory media: Creating spaces for storytelling in neighbourhood planning. In ACM CHI Conference on Human Factors in Computing Systems (pp. 1688-1701), New York, NY: Association for Computing Machinery. Retrieved from https://eprint.ncl.ac. uk/237163

McClure, W., Byrne, A., \& Hurand, F. (1997). Visualization techniques for citizen participation. In W. McClure (Ed.), The rural town: Designing for growth and sustainability. Moscow, ID: Center for Business Development and Research University of Idaho.

McCullough, M. (2005). Digital ground: Architecture, pervasive computing, and environmental knowing. Cambridge, MA: The MIT Press.

Natarajan, L. (2017). Socio-spatial learning: A case study of community knowledge in participatory spatial planning. Progress in Planning, 111, 1-23. http://dx. doi.org/10.1016/j.progress.2015.06.002

Norman, D. (2013). The design of everyday things (3rd ed.). New York, NY: Basic Books.

Nourian, P., Martinez-Ortiz, C., \& Ohori, K. A. (2018). Essential means for urban computing: Specification of web-based computing platforms for urban planning, a Hitchhiker's guide. Urban Planning, 3(1), 47-57.

Nuojua, J. (2010). WebMapMedia: A map-based Web application for facilitating participation in spatial planning. Multimedia Systems, 16, 3-21.
Paulini, M., Murty, P., \& Maher, M. L. (2013). Design processes in collective innovation communities: A study of communication. CoDesign, 9(2), 90-112. https:// doi.org/10.1080/15710882.2012.716850

Pietsch, S. M. (2000). Computer visualisation in the design control of urban environments: A literature review. Environment and Planning B: Planning and Design, 27(4), 521-536. https://doi.org/ $10.1068 / \mathrm{b} 2634$

Puussaar, A., Johnson, I. G., Montague, K., James, P., \& Wright, P. (2018). Making open data work for civic advocacy. Proceedings of the ACM on HumanComputer Interaction, 2(CSCW). https://doi.org/ 10.1145/3274412

Szell, M. (2018). Crowdsourced quantification and visualization of urban mobility space inequality. Urban Planning, 3(1), 1-12.

Talen, E. (2000). Bottom-up GIS: A new tool for individual and group expression in participatory planning. Journal of the American Planning Association, 66(3), 279-294. https://doi.org/10.1080/ 01944360008976107

Taylor, A. S., Lindley, S., Regan, T., Sweeney, D., Vlachokyriakos, V., Grainger, L., \& Lingel, J. (2015). Datain-place: Thinking through the relations between data and community. In Proceedings of the 33rd Annual ACM Conference on Human Factors in Computing Systems-CHI'15 (pp. 2863-2872). New York, NY: Association for Computing Machinery. https://doi. org/10.1145/2702123.2702558

Tufte, E. (2001). The visual display of quantitative information (2nd ed.). Cheshire, CT: Graphics Press.

Watson, V. (2020). Digital visualisation as a new driver of urban change in Africa. Urban Planning, 5(2), 1-9.

Weise, S. (2016). Infrastructures for participation: Institutional and technical considerations for new forms of participation in urban development (Unpublished Doctoral dissertation). Faculty of Science and Technology, School of Computing \& Communications, Lancaster University, UK. Retrieved from https:// eprints.lancs.ac.uk/id/eprint/79046

Wilson, A., \& Tewdwr-Jones, M. (2019). Let's draw and talk about urban change: Deploying digital technology to encourage citizen participation in urban planning. Environment and Planning B: Urban Analytics and City Science. Advance online publication. https:// doi.org/10.1177/2399808319831290

Wilson, A., Tewdwr-Jones, M., \& Comber, R. (2019). Urban planning, public participation and digital technology: App development as a method of generating citizen involvement in local planning processes. Environment and Planning B: Urban Analytics and City Science, 46(2), 286-302. https://doi.org/10.1177/ 2399808317712515 


\section{About the Authors}

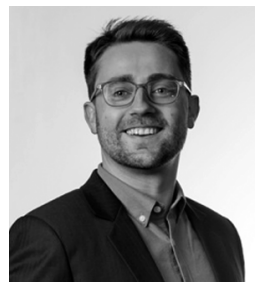

Sebastian Weise is Founder of PlaceChangers Ltd. and a Lecturer in Digital Civics at Newcastle's School for Architecture, Planning and Landscape. He earned a PhD in digital innovation from Lancaster University focusing on improvement of consultation processes in local government. He researches participatory processes within urban planning.

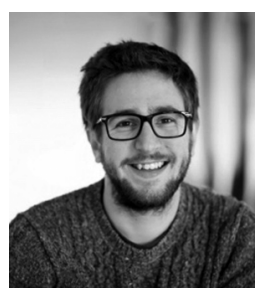

Alexander Wilson is a Researcher working between the School of Architecture, Planning and Landscape and Open Lab, School of Computing, at Newcastle University, UK. His research explores the intersections of digital technology, design, human-computer interaction and town planning, with a focus on alternative and enhanced tools and methods for participation in planning.

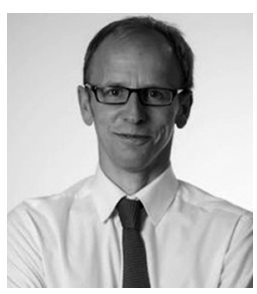

Geoff Vigar is Professor of Urban Planning in the School of Architecture, Planning and Landscape. He is also a co-leader of the "Digital Local Democracy" theme within the Digital Economy Research Centre at Open Lab. His research focuses on the design of institutions for more participatory and collaborative forms of urban governance. 